\title{
Sorption Equilibrium Moisture Characteristics of Selected Corn Stover Components
}

\author{
C. Igathinathane, A. R. Womac, S. Sokhansanj, L. O. Pordesimo
}

\begin{abstract}
Corn stover equilibrium moisture isotherms were developed to aide biomass engineering of consistent, uniform-quality feedstock supplies for renewable bioenergy and bioproducts. Equilibrium moisture content (EMC) and equilibrium relative humidity $(E R H)$ sorption data of corn leaf, stalk skin, and stalk pith were experimentally determined using the static gravimetric method at six temperatures ranging from $10^{\circ} \mathrm{C}$ to $40^{\circ} \mathrm{C}$ and at ten $E R H$ values ranging from 0.11 to 0.98. The greatest EMC values for corn leaf and stalk pith generally corresponded with ERH below and above 0.90, respectively, at all temperatures. Only at some intermediate ERH range at $20^{\circ} \mathrm{C}$ to $40^{\circ} \mathrm{C}$ was stalk skin EMC greater than stalk pith EMC. Corn stover components followed a type II isotherm typically observed among food materials. EMC of all components was proportional to ERH and inversely proportional to temperature. Observed EMC ranges were $3.9 \%$ to $56.4 \%$, $3.1 \%$ to $41.1 \%$, and $2.7 \%$ to $71.5 \%$ dry basis (d.b.) for corn leaf, stalk skin, and stalk pith, respectively. Calculated whole-stalk EMC values ranged from $3.1 \%$ to $49.2 \%$ d.b. Isotherm data were fitted with the EMC model of Henderson, and modified versions of Henderson, Chung-Pfost, Halsey, Oswin, and Guggenheim-Anderson-deBoer. The modified Oswin model $\left(R^{2}>\right.$ $0.98 ; F>2085)$ followed by the modified Halsey model $\left(R^{2}>0.97 ; F>1758\right)$ produced the best fit for corn stover components studied. The Henderson, modified Henderson, and modified Chung-Pfost models were not suitable since these models did not produce randomized residuals. The modified Oswin model $\left(R^{2}=0.99 ; F=6274\right)$ best described the stalk EMC. Results have practical applications in corn stover collection method and timing; process handling, grinding, and drying requirements; transportation efficiency of dry matter; and necessary storage environment, shelf life, and potential microorganism safety hazards. For example, results indicated that higher EMC values for corn stover leaf may result in greater propensity for the onset of mold growth and may determine minimal storage requirements or potential advantages in separating leaf from stalk fractions.
\end{abstract}

Keywords. Bioenergy, Biomass, Corn, Equilibrium, Isotherms, Moisture content, Relative humidity, Sorption, Storage, Stover.

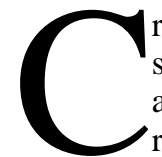

rop residues represent one sector of biomass feedstocks being examined for renewable bioenergy and bioproducts. Corn stover is an abundant crop residue that may have strategic value as an energy source once it is processed and converted (Sokhansanj et al., 2001). Approximately 200 million dry metric tons of annual U.S. corn stover were estimated as underutilized (Glassner et al., 1998). Successful processing and conversion of corn stover, or any other biological feedstock, depends on consistent availability of uniform quality feedstock. Moisture content is one of many factors affecting feedstock quality,

Article was submitted for review in October 2004; approved for publication by the Food \& Process Engineering Institute Division of ASAE in July 2005.

The authors are Igathinathane Cannayen, ASAE Member Engineer, Post-Doctoral Research Associate, and Alvin R. Womac, ASAE Member Engineer, Professor, Department of Biosystems Engineering and Environmental Science, The University of Tennessee, Knoxville, Tennessee; Shahab Sokhansanj, ASAE Member Engineer, Distinguished Research Scientist, Oak Ridge National Laboratory, Environmental Sciences Division, Oak Ridge, Tennessee; and Lester O. Pordesimo, ASAE Member Engineer, Agricultural Engineer, USDA-ARS Instrument and Sensing Lab, Beltsville, Maryland. Corresponding author: Alvin R. Womac, Department of Biosystems Engineering and Environmental Science, The University of Tennessee, 2506 E. J. Chapman Drive, Knoxville, TN 37996-4531; phone: 865-974-7104; fax: 865-974-4514; e-mail: awomac@utk.edu. material texture, microbial activity and growth, and storage stability. Environment temperature and relative humidity affect corn stover moisture, which in turn determines engineering design parameters for successful biomass collection, processing and transportation (Jenkins and Sumner, 1986), and storage. Aboveground components of the corn plant, minus grain and cob, are herein defined as corn stover. Stalk, leaf, and husk represent $60 \%, 25 \%$, and $15 \%$ of corn stover dry matter, respectively (Pordesimo et al., 2004).

Equilibrium moisture content (EMC) is a relevant physicochemical property describing the moisture state of a hygroscopic material as it equilibrates on a moisture basis with its environment. EMC data have practical application, such as helping establish humidity bounds to inhibit microbial growth and mycotoxin production during storage (Boente et al., 1996). Moisture isotherms describe the EMC as a function of the environment equilibrium relative humidity (ERH) (Bell and Labuza, 2000; Rahman, 1995) and are useful for biological materials (Iglesias and Chirife, 1976). A reliable method to determine sorption moisture isotherms is the static gravimetric method, which subjects test samples to the moisture-controlled environment created by saturated salt solutions until moisture equilibration (Bell and Labuza, 2000; Rahman, 1995).

Published studies on equilibrium moisture relations of biomass materials are not numerous, although related literature was found on food materials. Previous biomass 
equilibrium moisture research included alfalfa hay (Zink, 1935; Dexter et al., 1947) prairie hay, red clover hay, oat straw (Zink, 1935), wheat straw (Duggal and Muir, 1981), asparagus (Strahm et al., 1995), and biomass briquettes (Singh, 2004).

Chirife and Iglesias (1978), Van den Berg and Bruin (1981), and Wang and Brennan (1991) reviewed several mathematical isotherm models for various biological materials. Temperature level affects isotherms, and some models take this factor into account. Even though several isotherm models are available, no "universal model" adequately described sorption characteristics of cereal grains, seeds, and biological materials over a broad range of temperature and relative humidity (Chen and Morey, 1989; Sun and Woods, 1993). Selection of the appropriate isotherm model should be made specific to the material. Six candidate isotherm models for corn stover included the following: Henderson, modified Henderson, modified Chung-Pfost, modified Halsey, modified Oswin, and Guggenheim-Anderson-deBoer (GAB) (ASAE Standards, 2003a). The GAB model does not incorporate the effect of temperature; therefore, a modified GAB isotherm model to include temperature variation was developed (Jayas and Mazza, 1993; Menkov, 2000).

To summarize the research need, the lack of EMC data applicable to corn stover is a barrier in determining proper engineering design parameters for collection method and timing; process handling, grinding, and drying requirements; transportation efficiency of dry matter; and necessary storage environment, shelf life, and potential micro-organism safety hazards. EMC data on corn stover are an important component of the information needed to develop systems to supply consistent, uniform quality feedstock of an abundant crop residue for renewable bioenergy and bioproducts.

Thus, the overall objective was to determine EMC characteristics of corn stover to aid the resources available for biomass systems engineering. Specific objectives were as follows:

- To determine moisture sorption data of selected corn stover components such as corn leaf, stalk skin, and stalk pith at six different temperatures ranging from $10^{\circ} \mathrm{C}$ to $40^{\circ} \mathrm{C}$ at different ERH ranging from 0.11 to 0.98 .

- To evaluate a comprehensive selection of isotherm models for describing isotherm sorption data for the selected corn stover components.

\section{Materials AND Methods}

The approach focused on corn stover components with the greatest dry matter. So, the stalk (60\%) and leaf $(25 \%)$ (Pordesimo et al., 2004) were selected since they comprised $85 \%$ of the stover dry matter. It could be argued that husks have morphology that resembles leaves more than stalks, but the rationale for dropping husks was to accommodate greater test ranges in temperature and ERH for not unlimited resources. The stalk was physically divided into stalk skin and stalk pith components to test separately for two reasons. First, EMC is a final state assumed to be more affected by fundamental component material composition than by rate of mass transfer of a composite. Sample preparation should have had minimal impact since the magnitude of interface cell mass was low compared to stalk skin and stalk pith cell masses. It is acknowledged that some cell disturbance near tissue boundaries may have had some affect, but the affect was thought to be minimal. Second, testing whole stalks would have required several large environmental chambers that would have been more difficult to control than the selected salt solution method. The approach assumes that sorption isotherms are relevant to corn stover being harvested for biomass. Selection of a sorption study was driven mostly by the availability of a proven sorption test method and the difficulty in achieving high moisture content uniformity among natural samples. Hysteresis differences between sorption and desorption were not evaluated. The sorption-based study was relevant to stover allowed to naturally dry in the field prior to harvest.

\section{Sample Preparation}

Field corn variety Dekalb 743, planted on 20 May 2003 at The University of Tennessee Knoxville Experiment Station, was selected for the study. Corn stover stalk and leaf stocks were collected during typical crop grain harvest (24 September 2003), which coincided with grain moisture of about $25 \%$ wet basis. Airtight bags made of sheet polyethylene (clear, $152 \mu \mathrm{m}$ thick, Sunbelt Plastics, Monroe, La.) held samples stored at $-15^{\circ} \mathrm{C}$ in a laboratory freezer before isotherm experiments. Previous researchers (Boente et al., 1996; Fan et al., 2000; Basunia and Abe, 2001; and McNeill et al., 2001) stored samples in cold or cool storage for EMC experiments. Minimal moisture loss during storage was not evaluated, although sample moisture status before the experiments was determined and reported. Samples were equilibrated to ambient room conditions after removal from the freezer.

Corn leaves were cut into small pieces (fig. 1a) with scissors. The cross-sections of corn stalks were elliptical and geometrically considered as elliptical frustums. Stalks were composed of thick fibrous skin covering a spongy pith core. Stalk skin and stalk pith were treated as separate materials in the analysis. A bandsaw with a fine blade sectioned stalks into approximately $8 \mathrm{~mm}$ thick discs (fig. 1b) from random locations along the bottom two-thirds of the stalk length. Discs were manually separated into rings of stalk skin and discs of stalk pith. Stalk skin rings were manually broken into pieces (fig. 1c), and the stalk pith discs were cut into six to eight sectors (fig. 1d) with a sharp knife. Cutting operations could have disturbed cells near tissue boundaries.

Vernier calipers measured sample dimensions. Mean dimensions (50 replications) of samples are presented in table 1. Sample mass was determined with a digital balance (0.001 $\mathrm{g}$ resolution). Airtight polyethylene sample bags (clear, $102 \mu \mathrm{m}$ thick, Whirl-Pak, Nasco, Fort Atkinson, Wisc.) held samples prepped for experiments.

\section{Experimental Procedure}

Sorption isotherm data were collected using saturated salt solutions and gravimetric sample measures. Initial moisture contents of stover component samples were determined separately before moisture sorption experiments based on ASAE Standards (ASAE Standards, 2003b) for forage moisture determination. Glass desiccators with $100 \mathrm{~mm}$ inner diameter and $70 \mathrm{~mm}$ working height above the base plate provided the required airtight environment. Lower compartments of the desiccators, separated by perforated stainless steel base plates, held the different chemical salt solutions prepared with distilled water. All chemical salts 


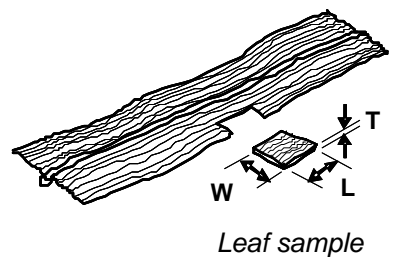

a. Leaf section

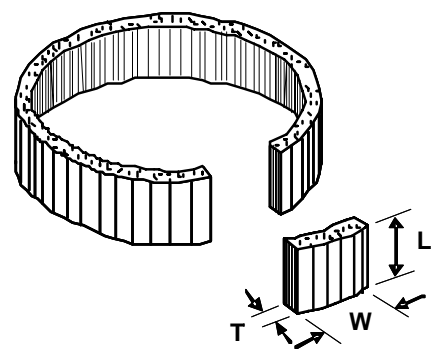

Stalk skin sample

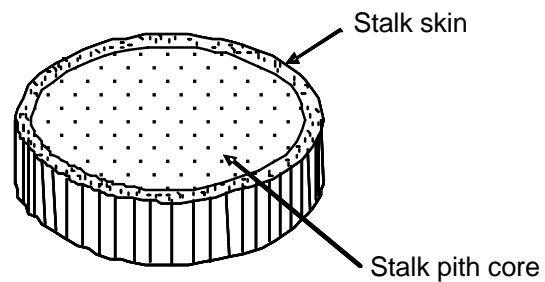

b. Cut stalk disc

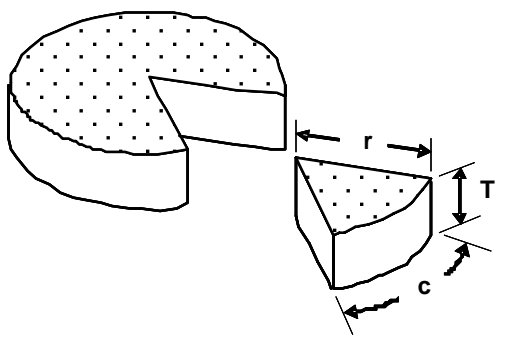

Stalk pith sample

c. Extracted stalk skin ring

d. Extracted stalk pith disc

Figure 1. Corn stover component sample preparation for sorption data collection.

Table 1. Weight proportions of stalk components and dimensions of prepared corn stover component samples.

\begin{tabular}{|c|c|c|c|c|c|c|}
\hline \multirow[b]{2}{*}{ Material } & \multicolumn{3}{|l|}{ Dimension $(\mathrm{mm})^{[\mathrm{a}]}$} & \multirow{2}{*}{$\begin{array}{c}\text { Stalk Weight } \\
\text { Proportion } \\
(\%)\end{array}$} & \multicolumn{2}{|c|}{$\begin{array}{l}\text { Initial Moisture } \\
\text { Content (\% d.b.) }\end{array}$} \\
\hline & Description & Mean & S.D. ${ }^{[b]}$ & & Mean & S.D. ${ }^{[b]}$ \\
\hline \multirow[t]{3}{*}{ Corn leaf } & L [length - measured along the fiber] & 11.25 & 1.78 & -- & 8.11 & 0.68 \\
\hline & W [width - measured perpendicular to fiber] & 9.46 & 1.48 & & & \\
\hline & $\mathrm{T}$ [thickness - measured perpendicular to L and W] & 0.17 & 0.02 & & & \\
\hline \multirow[t]{3}{*}{ Stalk skin } & L $\quad$ [length - measured along the fiber $]$ & 9.17 & 1.21 & 74.3 & 12.19 & 1.98 \\
\hline & W [width - measured perpendicular to fiber] & 7.93 & 1.66 & & & \\
\hline & $\mathrm{T}$ [thickness - measured perpendicular to L and W] & 1.22 & 0.35 & & & \\
\hline \multirow[t]{3}{*}{ Stalk pith } & $\mathrm{r} \quad$ [radius of sector] & 7.14 & 0.68 & 25.7 & 6.09 & 0.23 \\
\hline & c [sector curved chord length] & 7.78 & 1.10 & & & \\
\hline & $\mathrm{T}$ [thickness - measured along fiber] & 7.63 & 0.99 & & & \\
\hline
\end{tabular}

[a] Figure 1 shows specific orientation of dimension description variables.

[b] S.D. = standard deviation.

Table 2. ERH of selected saturated salt solutions at $10^{\circ} \mathrm{C}$ and $40^{\circ} \mathrm{C}$ (Greenspan, 1977).

\begin{tabular}{|c|c|c|c|}
\hline \multirow[b]{2}{*}{ Saturated Salt Solution } & \multirow{2}{*}{$\begin{array}{c}\text { Chemical } \\
\text { Formula }\end{array}$} & \multicolumn{2}{|c|}{ ERH (decimal) } \\
\hline & & $10^{\circ} \mathrm{C}$ & $40^{\circ} \mathrm{C}$ \\
\hline Lithium chloride & $\mathrm{LiCl}$ & 0.113 & 0.112 \\
\hline Potassium acetate ${ }^{[a]}$ & $\mathrm{CH}_{3} \mathrm{COOK}$ & 0.234 & 0.189 \\
\hline Magnesium chloride & $\mathrm{MgCl}_{2}$ & 0.335 & 0.316 \\
\hline Potassium carbonate & $\mathrm{K}_{2} \mathrm{CO}_{3}$ & 0.431 & $0.431^{[\mathrm{a}]}$ \\
\hline Magnesium nitrate & $\mathrm{Mg}\left(\mathrm{NO}_{3}\right)_{2} \cdot 6 \mathrm{H}_{2} \mathrm{O}$ & 0.574 & 0.484 \\
\hline Potassium iodide & $\mathrm{KI}$ & 0.721 & 0.661 \\
\hline Sodium chloride & $\mathrm{NaCl}$ & 0.757 & 0.747 \\
\hline Potassium chloride & $\mathrm{KCl}$ & 0.868 & 0.823 \\
\hline Potassium nitrate ${ }^{[\mathrm{b}]}$ & $\mathrm{KNO}_{3}$ & 0.960 & 0.890 \\
\hline Potassium sulfate & $\mathrm{K}_{2} \mathrm{SO}_{4}$ & 0.982 & 0.964 \\
\hline
\end{tabular}

[a] Extrapolated by cubical polynomial fit from the available ERH data $\left(10^{\circ} \mathrm{C}\right.$ to $\left.30^{\circ} \mathrm{C}\right)$.

[b] Not used at $10^{\circ} \mathrm{C}$ due to space limitation in incubator. used were of extra-pure laboratory or certified grade (Fisher Science Education, Burr Ridge, Ill.). Saturated salt solutions with excess salts gave the required ERH environments inside the desiccators. Excess salt in solution was required to compensate for the possible solution dilution by the liberated moisture from samples. The saturated salt solutions used in the desiccators are listed in table 2 . The ERH values of the saturated salt solutions at most of the temperatures considered between $10^{\circ} \mathrm{C}$ and $40^{\circ} \mathrm{C}$ were obtained directly from reported data (Greenspan, 1977). In some cases, polynomial extrapolation was used to obtain the required ERH values. ERH levels produced by different saturated salt solutions at the limiting temperatures $\left(10^{\circ} \mathrm{C}\right.$ and $\left.40^{\circ} \mathrm{C}\right)$ are presented in table 2 .

Glass beakers $(10 \mathrm{~mL}$ capacity, $22 \mathrm{~mm}$ inner diameter, $33 \mathrm{~mm}$ height) held samples of corn stover components. The beakers were washed, thoroughly cleaned with alcohol, and dried before use. Nine beakers (three replications each for 
corn leaf, stalk skin, and stalk pith) were arranged on the stainless steel base plate in each desiccator. Samples (6 to 10 pieces) with total weight of approximately $0.2 \mathrm{~g}$ of corn leaf, $0.8 \mathrm{~g}$ of stalk skin, and $0.15 \mathrm{~g}$ of stalk pith were added to each beaker. To allow visual observation of microbial growth during experiments, growth-suppressing chemicals like phenyl mercury acetate or thymol (Rahman, 1995) were not included in the desiccators. Desiccators loaded with samples and saturated salt solutions were then subjected to six temperature levels of $10^{\circ} \mathrm{C}, 20^{\circ} \mathrm{C}, 25^{\circ} \mathrm{C}, 30^{\circ} \mathrm{C}, 35^{\circ} \mathrm{C}$, and $40^{\circ} \mathrm{C}$. A digital iso-temperature incubator with refrigeration facility provided below-ambient temperature levels of $20^{\circ} \mathrm{C}$ and below, and a digital hot-air oven provided temperatures $25^{\circ} \mathrm{C}$ and above. Ten desiccators were used at all temperatures except at $10^{\circ} \mathrm{C}$ (table 2). Nine desiccators were used at $10^{\circ} \mathrm{C}$ due to space limitations in the incubator.

Gross sample mass per beaker was recorded twice weekly with a digital balance $(0.0001 \mathrm{~g}$ resolution). Experiments for each temperature were concluded after 26 days when sample constant mass (equilibrium) (0.001 g/96 h) was reached between consecutive measurements. Samples at EMC were tested for moisture content (ASAE Standards, 2003b) upon final removal from the controlled environments. Disposable gloves minimized sample contamination throughout experiments. The selected static gravimetric method of moisture isotherm data generation was similar to the methods followed by others (Sokhansanj et al., 1986; Jayas and Mazza, 1993; Yu et al., 1999). Onset of visible microbial growth was observed daily and status was recorded.

\section{Estimation of Corn Stalk EMC}

Estimates of stalk EMC were reconstituted from stalk skin and stalk pith components mass proportion, initial moisture content, and component EMC. It was assumed that the EMC of individual stalk skin and stalk pith components in their separate states represented these components in an intact stalk. Mass proportion and initial moisture content of the components gave the dry matter of stalk skin and stalk pith. Let $D_{s t}, D_{s}$, and $D_{p}$ represent dry matter masses of stalk, stalk skin, and stalk pith, respectively. The EMC of stalk was estimated from the moisture balance of the components as follows:

$$
M_{s t}=D_{s}^{\prime} M_{s}+D_{p}^{\prime} M_{p}
$$

where

$M_{s t}=$ estimated EMC of the stalk, \% dry basis (\% d.b.)

$D_{s}^{\prime}=$ dry matter mass fraction of stalk skin component (equals $D_{s} / D_{s t}$ )

$D_{p}^{\prime}=$ dry matter mass fraction of stalk pith component (equals $D_{p} / D_{s t}$ )

$M_{S}=$ observed EMC of stalk skin component (\% d.b.)

$M_{p}=$ observed EMC of stalk pith component (\% d.b.).

Estimated EMC values of stalk (eq. 1) generated from the observed component EMC values at different environmental conditions were subjected to isotherm model fitting. The above analysis (eq. 1) could serve as representative EMC estimates of stalk and needs further research for exact verification. The sample preparation procedure involving cutting operations could have damaged otherwise intact tissues in the stalk samples. However, the final state point of EMC should be minimally affected.

\section{Isotherm Model Selection and Evaluation}

Six isotherm models that incorporated temperature effects were investigated: Henderson and modified versions of Henderson, Chung-Pfost, Halsey, Oswin, and GAB. Model selection was based on ASAE Standards (ASAE Standards, 2003a). The Henderson model was included because of its simplicity, although recent industry adoption was limited. Transformation of selected ERH models produced the following EMC models:

Henderson model:

$$
M=\left[\frac{\ln \left(1-H_{r}\right)}{-A T}\right]^{\frac{1}{B}}
$$

Modified Henderson model:

$$
M=\left[\frac{\ln \left(1-H_{r}\right)}{-A(T+B)}\right]^{\frac{1}{C}}
$$

Modified Chung-Pfost model:

$$
M=\frac{-1}{C} \ln \left[\frac{\ln \left(H_{r}\right)(T+B)}{-A}\right]
$$

Modified Halsey model:

$$
M=\left[\frac{-\exp (A+B T)}{\ln \left(H_{r}\right)}\right]^{\frac{1}{C}}
$$

Modified Oswin model:

$$
M=(A+B T)\left[\frac{H_{r}}{1-H_{r}}\right]^{\frac{1}{C}}
$$

Modified GAB model:

$$
M=\frac{A(C / T) B H_{r}}{\left(1-B H_{r}\right)\left(1-B H_{r}+(C / T) B H_{r}\right)}
$$

where

$M \quad$ = equilibrium moisture content (\% d.b.)

$H_{r} \quad=$ equilibrium relative humidity (decimal)

$A, B, C=$ individual model dependent empirical constants

$T=$ temperature $\left({ }^{\circ} \mathrm{C}\right)$.

The non-linear regression procedure, PROC NLIN, of SAS version 9.0 (SAS, 2002) fitted EMC models (eqs. 2 through 7) and determined constants. The non-linear regression procedure minimized the sum of squares of deviation between the predicted and observed isotherm data in a series of iterations to solve the model. The NLIN procedure used the Gauss-Newton method to solve the models. Input data to the NLIN procedure were a series of temperature, ERH, and corresponding EMC values for a specific corn stover component. Performance of the isotherm models was evaluated using performance parameters for non-linear models, such as mean relative percent error $\left(E_{m}\right)$, standard error $\left(E_{S}\right)\left(\%\right.$ d.b.), coefficient of determination $\left(\mathrm{R}^{2}\right)$, and F-statistic values. Most published works (Chen and Morey, 1989; Menkov, 2000; Viswanathan et al., 2003) used these parameters in model performance analysis. In this study, the 
Table 3. Standard ERH and observed EMC data of corn leaf, stalk skin, and stalk pith and estimated stalk EMC at different temperatures by static gravimetric method.

\begin{tabular}{|c|c|c|c|c|c|c|c|c|}
\hline \multirow[b]{2}{*}{$\begin{array}{c}\text { Temperature } \\
\left({ }^{\circ} \mathrm{C}\right)\end{array}$} & \multirow[b]{2}{*}{$\begin{array}{c}\mathrm{ERH}^{[\mathrm{a}]} \\
\text { (decimal) }\end{array}$} & \multicolumn{2}{|c|}{ Corn Leaf } & \multicolumn{2}{|c|}{ Stalk Skin } & \multicolumn{2}{|c|}{ Stalk Pith } & \multirow{2}{*}{$\begin{array}{c}\text { Stalk } \\
\text { EMC } \\
\text { (\% d.b. })\end{array}$} \\
\hline & & $\begin{array}{l}\text { EMC }[\mathrm{b}] \\
\text { (\% d.b.) }\end{array}$ & $\begin{array}{l}\text { S.D.[c] } \\
\text { (\% d.b.) }\end{array}$ & $\begin{array}{l}\text { EMC }[\mathrm{b}] \\
\text { (\% d.b.) }\end{array}$ & $\begin{array}{l}\text { S.D.[c] } \\
\text { (\% d.b.) }\end{array}$ & $\begin{array}{l}\text { EMC } \\
\text { (\% d.b.) }\end{array}$ & $\begin{array}{l}\text { S.D. }{ }^{[c]} \\
\text { (\% d.b.) }\end{array}$ & \\
\hline 10 & 0.113 & 7.15 & 0.40 & 4.53 & 0.21 & 5.50 & 0.73 & 4.79 \\
\hline 10 & 0.234 & 8.11 & 0.63 & 6.26 & 0.18 & 6.92 & 0.21 & 6.44 \\
\hline 10 & 0.335 & 9.15 & 0.57 & 8.00 & 0.17 & 7.84 & 0.46 & 7.96 \\
\hline 10 & 0.431 & 10.76 & 0.52 & 9.17 & 0.22 & 10.05 & 0.84 & 9.41 \\
\hline 10 & 0.574 & 12.66 & 0.38 & 12.06 & 0.14 & 12.10 & 0.39 & 12.07 \\
\hline 10 & 0.721 & 16.52 & 0.51 & 15.24 & 0.05 & 16.10 & 0.50 & 15.47 \\
\hline 10 & 0.757 & 18.46 & 0.64 & 15.94 & 0.08 & 18.00 & 0.51 & 16.49 \\
\hline 10 & 0.868 & 24.49 & 0.64 & 21.00 & 0.57 & 28.40 & 1.48 & 22.98 \\
\hline 10 & 0.982 & 56.40 & 3.02 & 41.10 & 2.73 & 71.50 & 5.14 & 49.24 \\
\hline 20 & 0.113 & 6.55 & 1.42 & 3.92 & 0.13 & 4.23 & 0.84 & 4.00 \\
\hline 20 & 0.231 & 7.28 & 0.84 & 5.65 & 0.23 & 5.80 & 0.82 & 5.69 \\
\hline 20 & 0.331 & 8.32 & 0.47 & 7.06 & 0.13 & 6.90 & 0.60 & 7.02 \\
\hline 20 & 0.432 & 9.60 & 0.48 & 9.00 & 0.16 & 8.50 & 1.05 & 8.87 \\
\hline 20 & 0.544 & 11.24 & 0.65 & 10.88 & 0.32 & 10.00 & 0.83 & 10.64 \\
\hline 20 & 0.699 & 14.30 & 0.49 & 14.36 & 0.04 & 13.40 & 0.21 & 14.10 \\
\hline 20 & 0.755 & 15.57 & 0.08 & 15.39 & 0.29 & 14.70 & 1.72 & 15.21 \\
\hline 20 & 0.851 & 19.97 & 0.25 & 18.45 & 0.37 & 22.10 & 1.07 & 19.43 \\
\hline 20 & 0.946 & 32.71 & 0.72 & 29.32 & 1.73 & 47.60 & 0.38 & 34.22 \\
\hline 20 & 0.976 & 43.60 & 0.58 & 38.35 & 1.65 & 63.40 & 5.14 & 45.06 \\
\hline 25 & 0.113 & 6.03 & 0.26 & 3.96 & 0.16 & 4.60 & 0.30 & 4.13 \\
\hline 25 & 0.225 & 6.66 & 0.34 & 5.04 & 0.20 & 5.00 & 0.31 & 5.03 \\
\hline 25 & 0.328 & 7.54 & 0.38 & 6.57 & 0.10 & 5.80 & 0.81 & 6.36 \\
\hline 25 & 0.432 & 8.79 & 0.14 & 8.44 & 0.10 & 6.80 & 0.34 & 8.00 \\
\hline 25 & 0.529 & 10.61 & 0.63 & 10.41 & 0.32 & 7.90 & 2.14 & 9.74 \\
\hline 25 & 0.689 & 13.15 & 0.58 & 13.51 & 0.13 & 12.40 & 0.70 & 13.21 \\
\hline 25 & 0.753 & 14.99 & 0.96 & 15.13 & 0.38 & 13.10 & 0.66 & 14.59 \\
\hline 25 & 0.843 & 18.81 & 0.45 & 18.63 & 0.29 & 17.00 & 1.39 & 18.19 \\
\hline 25 & 0.936 & 28.14 & 0.89 & 26.95 & 0.55 & 37.60 & 4.33 & 29.80 \\
\hline 25 & 0.973 & 38.32 & 1.17 & 35.81 & 2.15 & 54.90 & 6.07 & 40.92 \\
\hline 30 & 0.113 & 5.15 & 2.65 & 3.27 & 0.05 & 3.98 & 0.26 & 3.46 \\
\hline 30 & 0.216 & 6.00 & 0.76 & 3.94 & 0.24 & 4.40 & 0.34 & 4.06 \\
\hline 30 & 0.324 & 6.35 & 0.30 & 5.95 & 0.05 & 4.70 & 1.42 & 5.62 \\
\hline 30 & 0.432 & 8.00 & 1.28 & 7.45 & 0.12 & 5.07 & 1.07 & 6.81 \\
\hline 30 & 0.514 & 9.45 & 1.17 & 9.30 & 0.63 & 6.80 & 1.26 & 8.63 \\
\hline 30 & 0.679 & 11.51 & 0.28 & 12.22 & 0.10 & 11.31 & 1.79 & 11.98 \\
\hline 30 & 0.751 & 13.19 & 0.84 & 14.20 & 0.29 & 12.00 & 0.39 & 13.61 \\
\hline 30 & 0.836 & 17.23 & 2.76 & 16.88 & 0.83 & 14.62 & 0.29 & 16.27 \\
\hline 30 & 0.923 & 25.04 & 0.25 & 21.75 & 0.71 & 28.80 & 1.03 & 23.64 \\
\hline 30 & 0.970 & 36.12 & 2.44 & 34.29 & 2.10 & 47.40 & 1.27 & 37.80 \\
\hline 35 & 0.113 & 4.56 & 0.19 & 3.39 & 0.08 & 2.66 & 0.33 & 3.19 \\
\hline 35 & 0.204 & 5.02 & 0.35 & 4.16 & 0.19 & 3.27 & 0.40 & 3.92 \\
\hline 35 & 0.321 & 5.73 & 0.09 & 5.42 & 0.17 & 3.58 & 0.50 & 4.93 \\
\hline 35 & $0.431^{[\mathrm{e}]}$ & 7.25 & 0.36 & 6.85 & 0.26 & 4.50 & 0.42 & 6.22 \\
\hline 35 & 0.499 & 8.04 & 0.14 & 8.22 & 0.33 & 5.36 & 0.59 & 7.45 \\
\hline 35 & 0.670 & 10.95 & 0.38 & 11.39 & 0.19 & 9.75 & 0.22 & 10.95 \\
\hline 35 & 0.749 & 12.74 & 0.10 & 13.48 & 0.04 & 10.90 & 0.12 & 12.79 \\
\hline 35 & 0.83 & 16.54 & 0.34 & 15.95 & 0.63 & 14.11 & 0.45 & 15.46 \\
\hline 35 & 0.908 & 22.66 & 0.68 & 20.72 & 0.60 & 24.00 & 1.88 & 21.60 \\
\hline 35 & 0.967 & 32.63 & 1.00 & 30.30 & 3.87 & 42.90 & 5.08 & 33.67 \\
\hline 40 & 0.112 & 3.90 & 2.85 & 3.14 & 0.27 & 2.80 & 1.53 & 3.05 \\
\hline 40 & 0.189 & 4.10 & 0.58 & 3.40 & 0.27 & 3.00 & 0.87 & 3.29 \\
\hline 40 & 0.316 & 5.40 & 0.37 & 4.80 & 0.10 & 3.30 & 2.21 & 4.40 \\
\hline 40 & $0.431^{[\mathrm{e}]}$ & 6.67 & 0.74 & 6.59 & 0.09 & 4.07 & 1.05 & 5.92 \\
\hline 40 & 0.484 & 7.30 & 0.84 & 7.52 & 0.33 & 4.70 & 2.60 & 6.76 \\
\hline 40 & 0.661 & 10.30 & 1.25 & 11.29 & 0.85 & 8.30 & 4.83 & 10.49 \\
\hline 40 & 0.747 & 12.00 & 3.41 & 13.00 & 0.34 & 10.30 & 1.64 & 12.28 \\
\hline 40 & 0.823 & 14.70 & 1.23 & 15.29 & 0.64 & 13.10 & 3.26 & 14.70 \\
\hline 40 & 0.890 & 19.90 & 0.76 & 18.20 & 0.29 & 19.49 & 2.63 & 18.55 \\
\hline 40 & 0.964 & 30.94 & 3.89 & 26.79 & 2.53 & 40.00 & 5.76 & 30.33 \\
\hline
\end{tabular}

[a] Direct ERH values from standard results (Greenspan, 1977).

[b] $\mathrm{EMC}=$ mean EMC value.

[c] S.D. = standard deviation.

[d] Stalk EMC values were estimated from stalk skin and stalk pith EMC values.

[e] Polynomial extrapolation $\left(y=3 \mathrm{E}-5 x^{3}-0.0025 x^{2}+0.0617 x+42.7 ; \mathrm{R}^{2}=1.0\right)$ from available $10^{\circ} \mathrm{C}$ to $30^{\circ} \mathrm{C}$ ERH values 
F-statistic value of fitted models was also tried as a performance parameter for model evaluation. Because of wide variation in the F-statistic values of the models, F-statistic value should make a better model performance parameter. PROC NLIN gave the F-statistic values directly with the fitted constants.

A model was considered superior than another if it produced smaller values of $E_{m}$ and $E_{s}$ and greater values of $\mathrm{R}^{2}$ and $\mathrm{F}$ than other models. Reported results (Boente et al., 1996; Soysal and Öztekin, 1999; Menkov, 2000; Viswanathan et al., 2003; Aviara et al., 2004) showed that $E_{m}, E_{s}$, and $\mathrm{R}^{2}$ did not always line up with the indicated performance ranking of the models. In such situations, $E_{\mathrm{S}}$ and $\mathrm{R}^{2}$ were typically prioritized. In conjunction with model performance parameters, residual plots assessed the adequateness of models. A model was considered acceptable if the residuals were uniformly scattered about the $x$-axis (independent variable), showing no systematic distribution or clear pattern of residuals in the positive and negative directions of the $y$-axis (dependent variable residuals). When a residual plot of a model indicated a systematic distribution or clear pattern, the model was not accepted (Chen and Morey, 1989; Soysal and Öztekin, 1999). In this study, model residual plots had the input ERH values on the $x$-axis and EMC residuals on the $y$-axis.

\section{Results AND DiscuSSION \\ Observed EMC of Corn Stover Components}

ERH and mean EMC data of corn leaf, stalk skin, and stalk pith, and the estimated EMC values of stalk at different temperatures are presented in table 3. EMC generally increased with increasing ERH for all corn stover components at all temperatures. EMC values of corn leaf were the highest among all components at all temperatures with ERH below 0.90. EMC values of corn leaf were greater than that of stalk skin and stalk pith, perhaps due to inherent material differences. Stalk skin had greater EMC values than stalk pith with ERH below 0.23 at temperatures of $35^{\circ} \mathrm{C}$ and $40^{\circ} \mathrm{C}$, but stalk pith had higher EMC values in the temperature range of $10^{\circ} \mathrm{C}$ to $30^{\circ} \mathrm{C}$. It was observed that stalk skin EMC values were greater than that of stalk pith in some intermediate ERH range with temperature ranging from $20^{\circ} \mathrm{C}$ to $40^{\circ} \mathrm{C}$ (table 3 ).

Based on tissue structure, stalk skin was fibrous and readily absorbed moisture, whereas the stalk pith may have repelled moisture due to encapsulated air in the spongy material matrix. Stalk pith enclosed more closed cells than the stalk skin pieces. At ERH conditions greater than 0.90, stalk pith had the greatest EMC values, followed by corn leaf and stalk skin at all temperatures. EMC characteristics of other morphological components of corn stover such as husk, mid-rib of leaf, and skin and pith of stalk nodes require further research.

The highest temperature $\left(40^{\circ} \mathrm{C}\right)$ and the lowest $\mathrm{ERH}$ (0.11) combination produced the minimum EMC values, and the lowest temperature $\left(10^{\circ} \mathrm{C}\right)$ and the highest ERH $(0.98)$ combination produced the maximum EMC values with all components studied (table 3 ). The observed minimum and maximum EMC values were $3.9 \%$ and $56.4 \%$ d.b., $3.1 \%$ and $41.1 \%$ d.b., and $2.7 \%$ and $71.5 \%$ d.b., for corn leaf, stalk skin, and stalk pith, respectively. Overall mean EMC values of corn leaf, stalk skin, and stalk pith from the complete data were $14.7 \pm 10.8 \%$ d.b., $13.4 \pm 9.4 \%$ d.b., and $15.4 \pm 15.9 \%$ d.b., respectively.

Mold growth was observed on all components at ERH greater than 0.90. Mold growth may offer another mechanism affecting sample moisture. Since samples were not cleaned of mold growth before EMC determination, mold growth may have influenced EMC determinations. However, observed isotherm data with mold infestation were used in the analyses since EMC values at ERH above 0.90 did not show any abrupt departure from the smooth increasing trend.

Leaf components tended to have higher EMC values than stalk components for a given environment temperature and relative humidity. It can be concluded that the storage stability of corn leaf will be affected first, followed by stalk skin and stalk pith at storage environmental condition conducive for spoilage. Efficient storage may require separation of components, especially removal of mold-sensitive leaf components, and separate storage under specific environmental conditions.

\section{Calculated EMC of Corn Stalk}

Dry matter of stalk skin and stalk pith components was calculated as 0.66 and $0.24 \mathrm{~kg}$ (1 kg wet stalk basis), respectively, from the initial moisture content and weight proportion of stalk skin and stalk pith (table 1). Estimated EMC values of stalk (eq. 1) are also presented in table 3. The EMC values of stalk ranged from $3.1 \%$ to $49.2 \%$ d.b. Overall mean EMC of stalk was estimated as $13.9 \pm 11.1 \%$ d.b. by combining data at all temperatures. EMC values of stalk were more influenced by stalk skin than by stalk pith. This was because of stalk skin's greater weight proportion $(74.3 \%)$ in stalk, and because the stalk skin had higher EMC values at most ERH and temperature conditions than the stalk pith.

\section{ISOTHERMS FitTING AND EvALUATION}

The fitted isotherm constants and parameters indicating goodness of model fit are listed in table 4. Performance parameters differed to some extent in indicating the best-fit models. Table 4 shows that the performance parameters $E_{S}$ and $\mathrm{R}^{2}$ followed a similar pattern among models and corn stover components, but the $E_{m}$ pattern deviated more from that of the other parameters. Such deviations among performance parameters have been frequently encountered (Boente et al., 1996; Soysal and Öztekin, 1999; Menkov, 2000; Viswanathan et al., 2003; Aviara et al., 2004). The pattern in F-statistic values resembled the $E_{S}$ and $\mathrm{R}^{2}$ patterns. However, most of these performance parameters coincided in indicating modified Oswin as the best performing model for all corn stover components. The F-statistic value examined in this study, as a performance parameter for non-linear sorption isotherm fitting, is recommended for ranking the models based on its wide range and good performance.

The Henderson model did not produce acceptable performance. The other five models with three constants gave better performance than the Henderson model. Models for corn stover components ranked in order of decreasing performance were modified Oswin, modified Halsey, modified Henderson, modified GAB, modified Chung-Pfost, and Henderson.

Residual patterns of modified Oswin and modified Halsey for all components, and modified GAB except for stalk pith, showed random distribution, make only these three models 
Table 4. Fitted isotherm parameters for the corn leaf, stalk skin, stalk pith, and stalk of corn stover. ${ }^{[a]}$

\begin{tabular}{|c|c|c|c|c|c|c|c|c|c|}
\hline Material & Equation & $A$ & $B$ & C & $\begin{array}{l}E_{m} \\
(\%)\end{array}$ & $\begin{array}{c}E_{S} \\
(\% \text { d.b. })\end{array}$ & $\mathrm{F}$ & $\mathrm{R}^{2}$ & $\begin{array}{l}\text { Residual } \\
\text { Classification }\end{array}$ \\
\hline Corn & Henderson & 0.000629 & 1.6055 & -- & 17.64 & 4.37 & 481.69 & 0.8402 & Systematic \\
\hline \multirow[t]{5}{*}{ Leaf } & Modified Henderson & 0.000919 & 36.9385 & 1.1451 & 19.32 & 2.18 & 1355.94 & 0.9612 & Systematic \\
\hline & Modified Chung-Pfost & 104.6 & 13.3332 & 0.1296 & 21.35 & 3.10 & 327.43 & 0.9212 & Systematic \\
\hline & Modified Halsey & 5.5105 & -0.0255 & 2.2923 & 6.49 & 0.83 & 9423.78 & 0.9943 & Random \\
\hline & Modified Oswin & 12.8146 & -0.1167 & 2.5634 & 6.03 & 0.78 & 10762.80 & 0.9950 & Random \\
\hline & Modified GAB & 4.4520 & 0.9127 & 14932.6 & 13.88 & 2.84 & 785.07 & 0.9336 & Random \\
\hline Stalk & Henderson & 0.000403 & 1.8081 & -- & 18.81 & 4.15 & 427.32 & 0.8093 & Systematic \\
\hline \multirow[t]{5}{*}{ skin } & Modified Henderson & 0.000472 & 73.5802 & 1.2425 & 11.17 & 1.30 & 3066.51 & 0.9815 & Systematic \\
\hline & Modified Chung-Pfost & 166.5 & 34.7830 & 0.1434 & 13.23 & 1.66 & 905.39 & 0.9700 & Systematic \\
\hline & Modified Halsey & 5.3053 & -0.0126 & 2.4065 & 17.23 & 1.54 & 2180.21 & 0.9741 & Random \\
\hline & Modified Oswin & 10.8041 & -0.0580 & 2.7102 & 9.00 & 0.99 & 5344.86 & 0.9894 & Random \\
\hline & Modified GAB & 5.0314 & 0.8768 & 348.7 & 8.64 & 1.73 & 1739.88 & 0.9676 & Random \\
\hline Stalk & Henderson & 0.00147 & 1.2860 & -- & 30.38 & 7.54 & 222.54 & 0.7780 & Systematic \\
\hline \multirow[t]{5}{*}{ pith } & Modified Henderson & 0.00190 & 68.7153 & 0.7616 & 29.09 & 2.80 & 1198.29 & 0.9700 & Systematic \\
\hline & Modified Chung-Pfost & 65.6488 & 14.5591 & 0.0912 & 54.94 & 5.89 & 182.08 & 0.8667 & Systematic \\
\hline & Modified Halsey & 3.7938 & -0.0174 & 1.7461 & 16.49 & 2.31 & 1758.35 & 0.9795 & Random \\
\hline & Modified Oswin & 10.6099 & -0.0946 & 1.9136 & 14.95 & 2.13 & 2085.33 & 0.9826 & Random \\
\hline & Modified GAB & 9.8813 & 0.8924 & 9.1622 & 38.29 & 3.15 & 939.99 & 0.9619 & Random \\
\hline \multirow[t]{6}{*}{$\operatorname{Stalk}^{[\mathrm{b}]}$} & Henderson & 0.00067 & 1.6039 & -- & 19.54 & 5.01 & 347.39 & 0.8025 & Systematic \\
\hline & Modified Henderson & 0.00085 & 65.2487 & 1.0587 & 17.33 & 1.74 & 2011.15 & 0.9760 & Systematic \\
\hline & Modified Chung-Pfost & 115.7 & 25.1278 & 0.1244 & 23.59 & 2.74 & 447.54 & 0.9411 & Systematic \\
\hline & Modified Halsey & 4.7669 & -0.0153 & 2.1592 & 14.29 & 1.45 & 2911.00 & 0.9834 & Random \\
\hline & Modified Oswin & 10.9137 & -0.0746 & 2.4116 & 6.65 & 0.99 & 6273.97 & 0.9923 & Random \\
\hline & Modified GAB & 4.3589 & 0.9153 & 502.6 & 11.15 & 2.16 & 1311.17 & 0.9634 & Random \\
\hline
\end{tabular}

[a] Smaller values of $E_{m}$ and $E_{S}$ and greater values of $\mathrm{F}$ and $\mathrm{R}^{2}$ indicate better model performance.

[b] Stalk EMC values were estimated by combining the stalk skin and stalk pith components data.

acceptable (fig. 2). Henderson, modified Henderson, and modified Chung-Pfost showed a systematic distribution, and these models generally were not acceptable based on residual patterns, although modified Henderson and modified ChungPfost had acceptable values of performance parameters (table 4). Hence, based on prediction capabilities and randomized residuals, the modified Oswin isotherm model ( $\mathrm{R}^{2}=0.98$ to $0.995 ; \mathrm{F}=2085$ to 10763 ) was considered best for corn stover component moisture sorption isotherm analysis. Several studies with biological materials (Chen and Morey, 1989; Soysal and Öztekin, 1999; Yu et al., 1999; Menkov, 2000; Aviara et al., 2004) reported good prediction performance of the modified Oswin isotherm model. The modified Halsey model $\left(\mathrm{R}^{2}=0.97\right.$ to $0.99 ; \mathrm{F}=1758$ to 9424$)$ placed a close second. Thus, the modified Oswin and modified Halsey isotherm models are recommended for corn stover components.

Table 4 also shows the fit of different isotherm models for the estimated EMC values of stalk. The modified Oswin isotherm model $\left(\mathrm{R}^{2}=0.99 ; \mathrm{F}=6274\right)$ again emerged as the best model, and the second best model was modified Halsey $\left(\mathrm{R}^{2}=0.98 ; \mathrm{F}=2911\right)$ based on the performance parameters. Therefore, subsequent prediction analysis was carried out using the modified Oswin isotherm model. It should be understood that the stalk skin and stalk pith components when intact in stalk were expected to offer more resistance to moisture exchange than they do as individual constituents. As a result, the actual EMC value of stalk may be lower than that estimated from individual components.

\section{Prediction of EMC by Modified Oswin Model}

The modified Oswin isotherm model (table 4) was used to generate the predicted sorption isotherm of corn stover components. Predicted and observed EMC for corn leaf, stalk skin, and stalk pith at temperatures from $10^{\circ} \mathrm{C}$ to $40^{\circ} \mathrm{C}$ are plotted in figures 3,4 , and 5 , respectively. The plotted isotherms of corn stover components followed type II isotherms (Bell and Labuza, 2000). Type II isotherms are commonly observed among food materials, where an increase in temperature reduces the EMC. This EMC-reducing effect of the increased temperatures is in agreement with studies on various biological materials (Chen and Jayas, 1998; ASAE Standards, 2003a; Viswanathan et al., 2003).

The predicted isotherms (figs. 3, 4, and 5) show the good fit of the modified Oswin model, and the arrangement of curves depicts the reduction of EMC with increase in temperature. All corn stover components produced a sharp increase in EMC at ERH greater than 0.80, which is a common feature of type II isotherms of food materials. Moisture isotherms of all components were closer at ERH values less than about 0.50 , and they gradually separated at ERH above 0.50. Stalk pith obtained greater EMC at ERH above 0.80 , whereas corn leaf and stalk skin had relatively smaller EMC values. Closer arrangement of the stalk skin and stalk pith isotherms signified that the temperature had relatively less effect on the EMC of these components than on the EMC of corn leaf. Temperature change influenced stalk pith EMC values more than stalk skin EMC. To make the results more accessible, a combined plot of modified Oswin model predictions with converted units of EMC in \% wet basis and \% ERH of leaf, stalk skin, and stalk pith is plotted in figure 6. Figure 6 also shows the developed modified Oswin equations (table 4) with usual notations (eq. 6) and the predicted sorption isotherms at temperature limits of $10^{\circ} \mathrm{C}$ and $40^{\circ} \mathrm{C}$. 

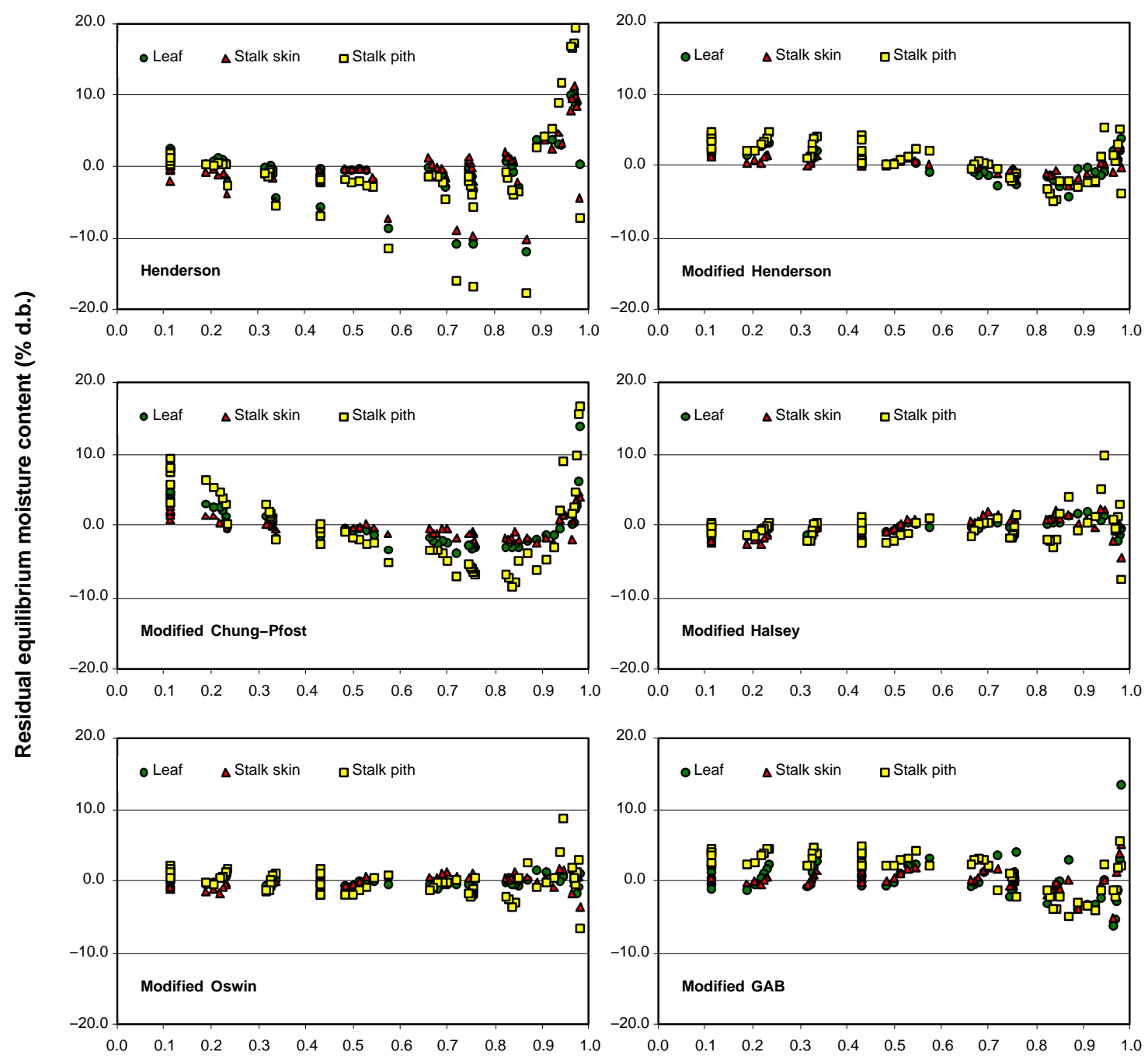

Equilibrium relative humidity (decimal)

Figure 2. Residual plots of the fitted isotherm equations for the moisture isotherm data of corn stover components at temperatures of $10^{\circ} \mathrm{C}$ to $40^{\circ} \mathrm{C}$.

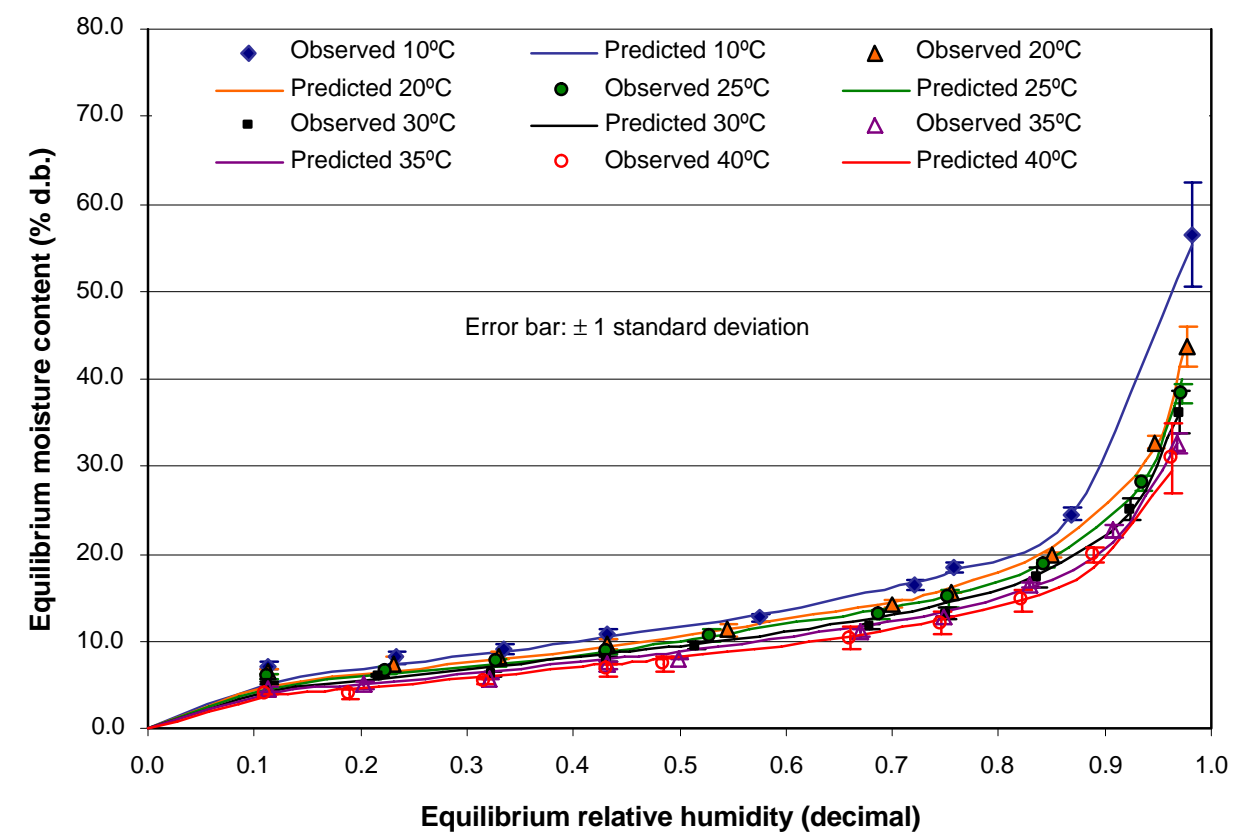

Figure 3. Comparison between observed and modified Oswin equation predicted sorption isotherms of corn leaf at controlled temperatures. 


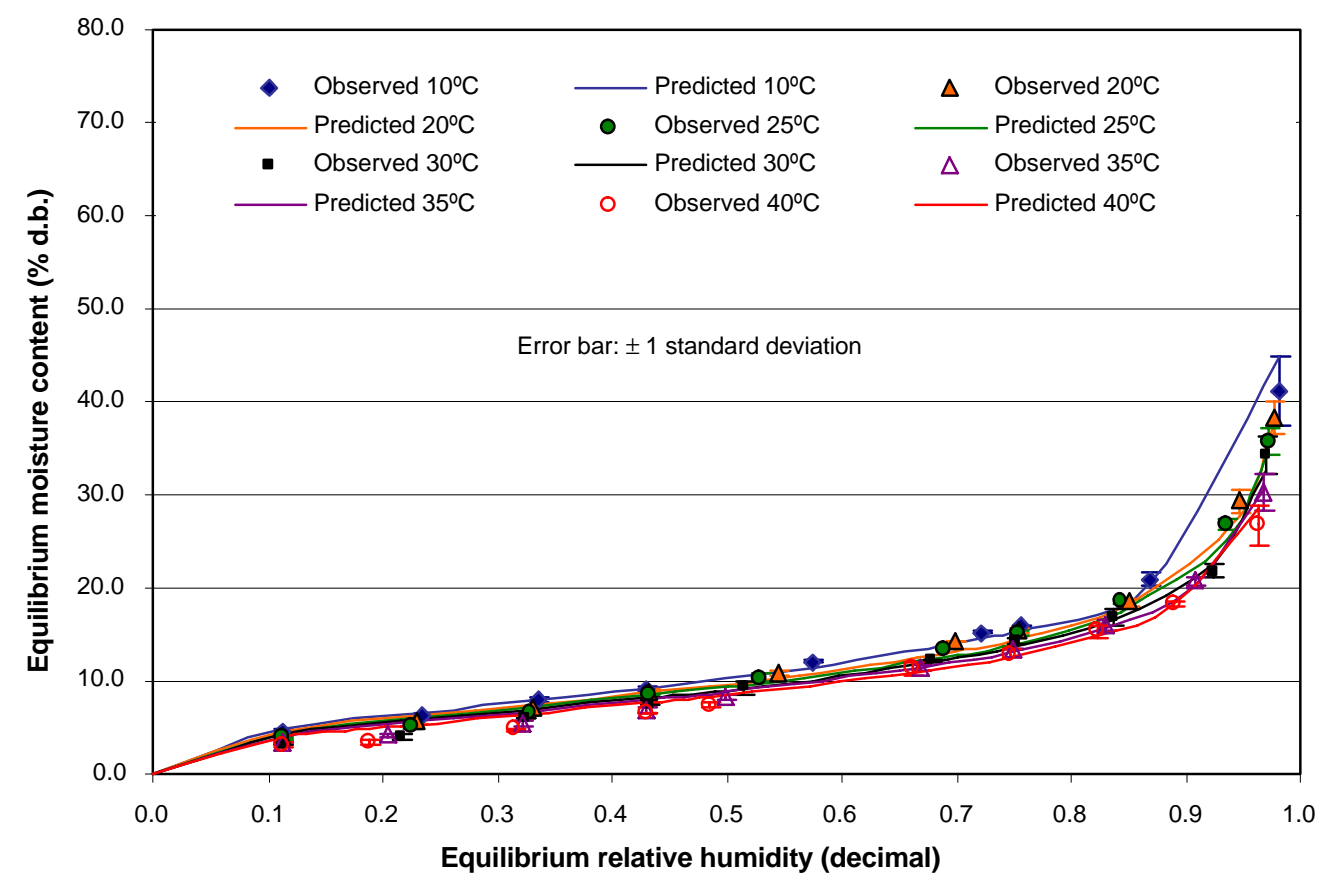

Figure 4. Comparison between observed and modified Oswin equation predicted sorption isotherms of corn stalk skin at controlled temperatures.

Comparison between estimated and modified Oswin model predicted EMC values for corn stalk is shown in figure 7, and EMC residuals of prediction are shown in figure 8. Stalk isotherms resembled stalk skin isotherms because of the greater weight and moisture contribution from the stalk skin component. Stalk isotherms belong to the type II isotherm classification. Randomized residuals of prediction determined the acceptability of the modified Oswin isotherm model (fig. 8). The closeness of residuals with the $x$-axis demonstrated the good prediction of the modified Oswin isotherm model.

\section{Conclusions}

The following conclusions were made from this study:

- Observed EMC of corn leaf, stalk skin, and stalk pith ranged from $3.9 \%$ to $56.4 \%$ d.b., $3.1 \%$ to $41.1 \%$ d.b., and $2.7 \%$ to $71.5 \%$ d.b., respectively. Overall mean EMC of corn leaf, stalk skin, and stalk pith in the temperature range of $10^{\circ} \mathrm{C}$ to $40^{\circ} \mathrm{C}$ were determined as $14.7 \%, 13.4 \%$, and $15.4 \%$ d.b., respectively.

- Corn leaf had the greatest EMC values among the components at ERH values below 0.90, and stalk pith had the greatest values at ERH above 0.90, at all tempera-

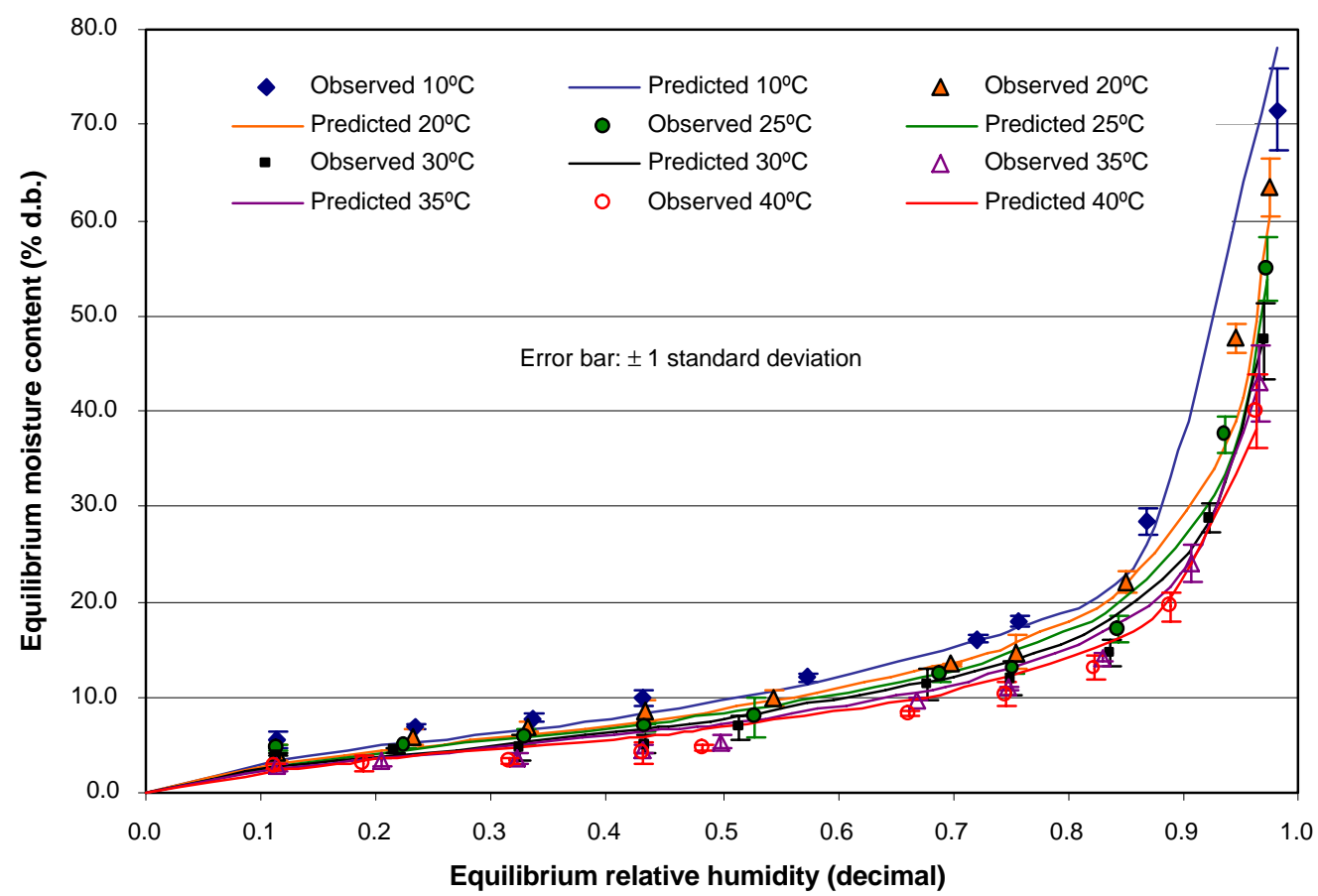

Figure 5. Comparison between observed and modified Oswin equation predicted sorption isotherms of corn stalk pith at controlled temperatures. 


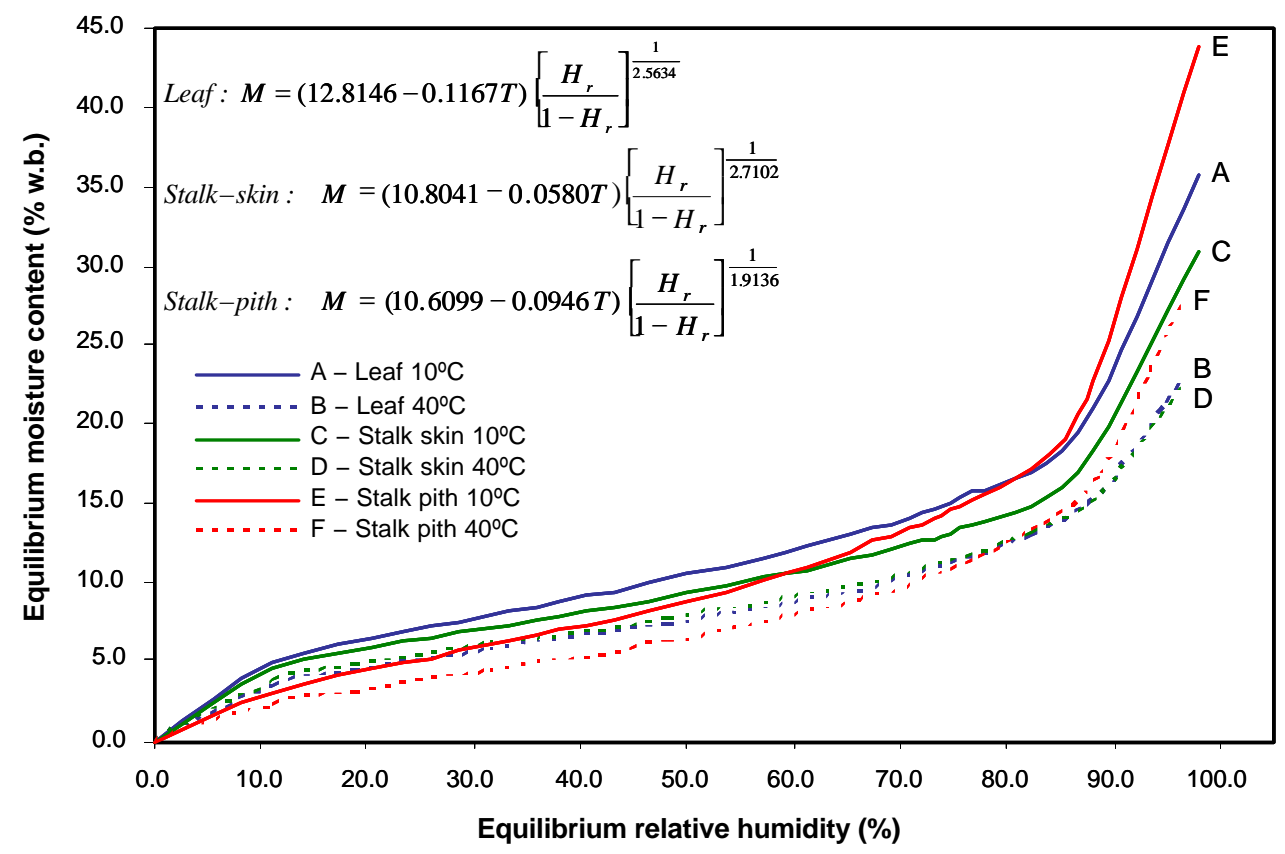

Figure 6. Modified Oswin equation predicted sorption isotherms models of corn leaf, stalk skin, and stalk pith at controlled temperature limits of $10^{\circ} \mathrm{C}$ and $40^{\circ} \mathrm{C}$.

tures. The higher EMC values for leaf at typical ambient conditions may result in greater propensity for onset of mold growth and may determine minimal storage requirements or potential advantages in separating leaf from stalk fractions.

- Calculated sorption EMC values for corn stalk ranged from $3.1 \%$ to $49.2 \%$ d.b. Future corn stalk EMC studies are recommended using large controlled-environment chambers so that stalks are not dissected for study.
Large-scale stalk studies more closely represent preharvest of stalks standing in the field.

- Sorption isotherms of corn leaf, stalk skin, stalk pith, and stalk followed a type II classification, which is typically observed among many food materials. Biological materials, whether classed as food or lignocellulose, exhibit similar isotherm behaviors, although the model constants are different.

- The EMC of all components was proportional to ERH and inversely proportional to temperature. Tempera-

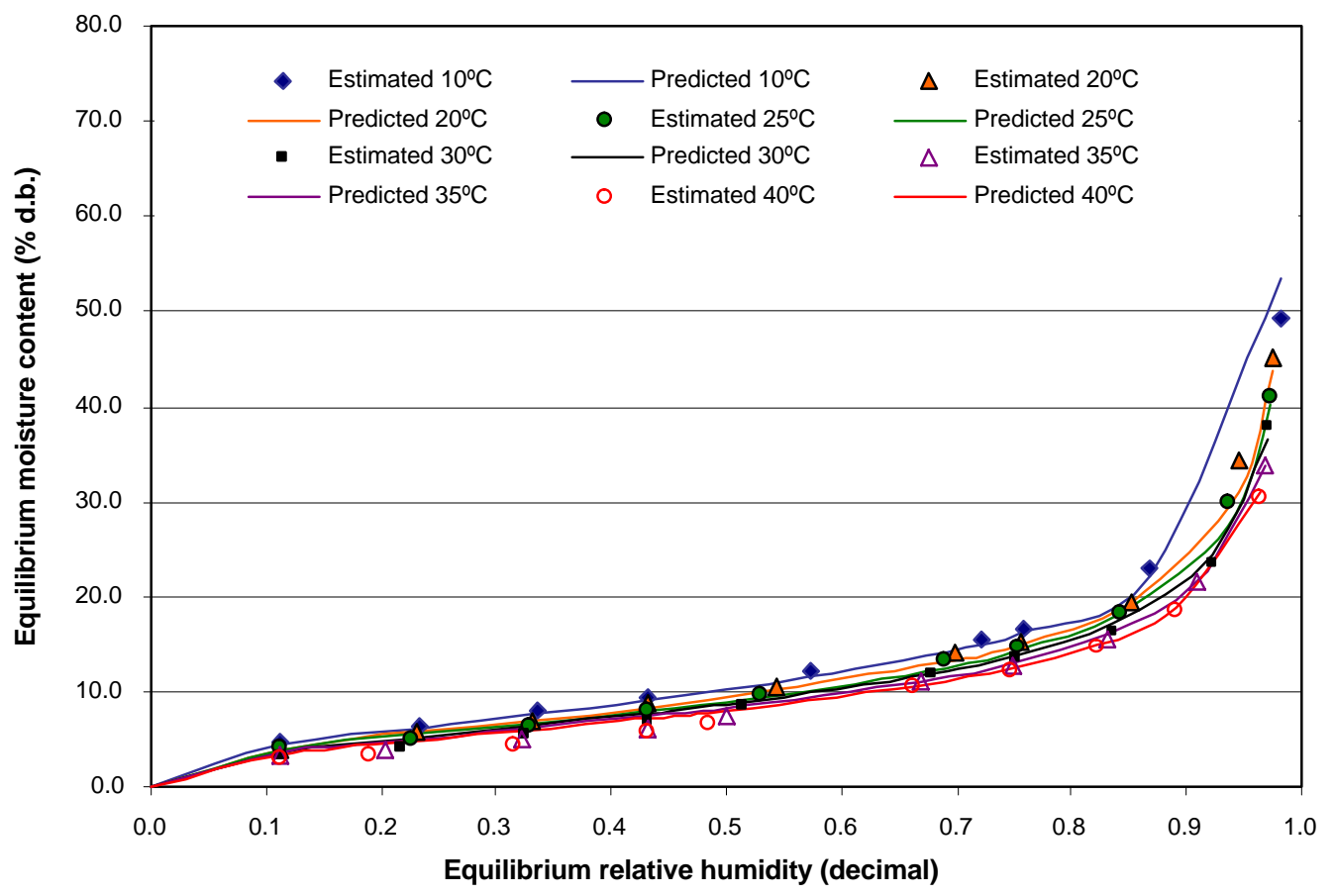

Figure 7. Comparison between estimated and modified Oswin equation predicted sorption isotherms of corn stalk at controlled temperatures and residuals of prediction. 


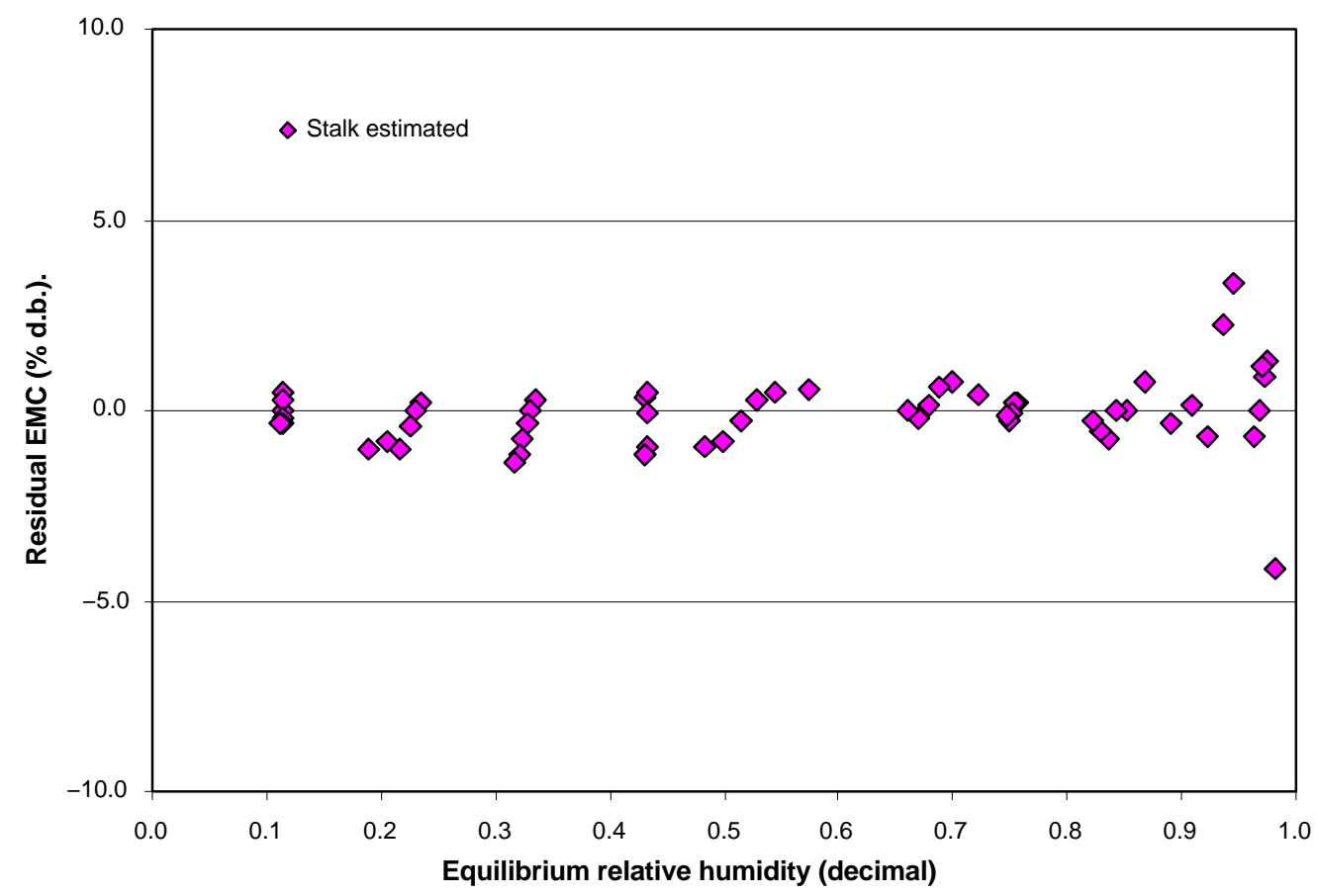

Figure 8. Residuals of prediction between estimated and modified Oswin equation predicted sorption isotherms of corn stalk at controlled temperatures.

ture change had a greater influence on EMC of corn leaf, followed by stalk pith and stalk skin. Moistureand temperature-sensitive leaf materials may control design and management criteria for corn stover biomass handling, processing, and storage.

- The modified Oswin isotherm model $\left(\mathrm{R}^{2}=0.98\right.$ to $0.995 ; \mathrm{F}=2085$ to 10763 ) was recommended for the moisture sorption isotherm analysis of corn leaf, stalk skin, and stalk pith components, based on its performance and randomized residuals of EMC. The next best model with randomized residuals was the modified Halsey model $\left(\mathrm{R}^{2}=0.97\right.$ to $0.99 ; \mathrm{F}=1758$ to 9424).

- The modified Oswin isotherm model fitted to the estimated sorption EMC of corn stalk gave good prediction $\left(\mathrm{R}^{2}=0.99 ; \mathrm{F}=6274\right)$ and produced randomized residuals.

\section{ACKNOWLEDGEMENTS}

Partial financial support by the Bioenergy Feedstock Development Program of the Oak Ridge National Laboratory with Subcontract No. 34000008088 is highly appreciated. Thanks are also due to Dr. Svetlana Zivanovic, Assistant Professor, Department of Food Science and Technology, and Dr. Mark Radosevich, Associate Professor, Department of Biosystems and Environmental Science, of The University of Tennessee, Knoxville, for extending their laboratory facilities.

\section{REFERENCES}

ASAE Standards. 2003a. D245.5: Moisture relationships of plant-based agricultural products. St. Joseph, Mich.: ASAE. ASAE Standards. 2003b. S358.2: Moisture measurement - forages. St. Joseph, Mich.: ASAE.
Aviara, N. A., O. O. Ajibola, and S. A. Oni. 2004. Sorption equilibrium and thermodynamic characteristics of soya bean. Biosystems Eng. 87(2): 179-190.

Basunia, M. A., and T. Abe. 2001. Moisture desorption isotherms of medium-grain rough rice. J. Stored Prod. Res. 37(3): 205-219.

Bell, L. N., and T. P. Labuza. 2000. Moisture Sorption - Practical Aspects of Isotherm Measurement and Use. St. Paul, Minn.: American Association of Cereal Chemists.

Boente, G., H. H. L. González, E. Martínez, M. L. Pollio, and S. L. Resnik. 1996. Sorption isotherms of corn-study of mathematical models. J. Food Eng. 29(1): 115-128.

Chen, C., and D. S. Jayas. 1998. Dynamic equilibrium moisture content for grain drying. Canadian Agric. Eng. 40(4): 299-303.

Chen, C. C., and R. V. Morey. 1989. Comparison of four RMC/ERH equations. Trans. ASAE 32(3): 983-989.

Chirife, J., and H. A. Iglesias. 1978. Equations for fitting water sorption isotherms of food: Part I - A review. J. Food Tech. 13(3): 159-174

Dexter, S. T., W. H. Sheldon, and D. I. Waldron. 1947. Equilibrium moisture content of alfalfa hay. Agric. Eng. 28(7): 295-296.

Duggal, A. K., and W. E. Muir. 1981. Adsorption equilibrium moisture content of wheat straw. J. Agric. Eng. Res. 26(4): 315-320.

Fan, J., T. J. Siebenmorgen, and B. P. Marks. 2000. Effects of variety and harvest moisture content on equilibrium moisture contents of rice. Applied Eng. in Agric. 16(3): 245-251.

Glassner, D. A., J. R. Hettenhaus, and T. M. Schechinger. 1998. Corn stover potential: Recasting the corn sweetener industry. In Proc. 4th National New Crop Symposium: Perspectives on New Crops and New Uses, 74-82. Alexandria, Va.: ASHS Press.

Greenspan, L. 1977. Humidity fixed points of binary saturated aqueous solutions. J. Res. Natl. Bureau of Standards, Section A. Physics and Chemistry 81: 89-102.

Iglesias, H. A., and J. Chirife, J. 1976. Isosteric heats of water vapor sorption on dehydrated foods: Part I. Analysis of the differential heat curves. Lebensmittel Wissenschaft und Technology 9(2): 116-122.

Jayas, D. S., and G. Mazza. 1993. Comparison of five three-parameter equations for the description of adsorption data of oats. Trans. ASAE 36(1): 119-125. 
Jenkins, B. M., and H. R. Sumner. 1986. Harvesting and handling agricultural residues for energy. Trans. ASAE 29(3): 824-836.

McNeill, S. G., Z. A. Henry, L. R. Wilhelm, and L. R. Walton. 2001. Delayed harvest effects on moisture sorption properties of soybeans. Applied Eng. in Agric. 17(3): 329-340.

Menkov, N. D. 2000. Moisture sorption isotherms of vetch seeds at four temperatures. J. Agric. Eng. Res. 76(4): 373-380.

Pordesimo, L. O., W. C. Edens, and S. Sokhansanj. 2004. Distribution of aboveground biomass in corn stover. Biomass and Bioenergy 26(4): 337-343.

Rahman, S. 1995. Water activity and sorption properties of food. In Food Properties Handbook, 1-86. Boca Raton, Fla.: CRC Press.

SAS. 2002. SAS version 9 online help and documentation. Cary, N.C.: SAS Institute, Inc.

Singh, R. N. 2004. Equilibrium moisture content of biomass briquettes. Biomass and Bioenergy 26(3): 251-253.

Sokhansanj, S., W. Zhijie, D. Jayas, and T. Kameoka. 1986. Equilibrium relative humidity - moisture content of rapeseed (canola) from $5^{\circ} \mathrm{C}$ to $25^{\circ} \mathrm{C}$. Trans. ASAE 29(3): 837-839.

Sokhansanj, S., J. Cushman, A. Turhollow, and J. Cundiff. 2001. Biomass feedstock supply - Corn stover collection, cost estimates, proposed research, and development programs. ASAE Paper No. 016047. St Joseph, Mich.: ASAE.
Soysal, Y., and S. Öztekin. 1999. Equilibrium moisture content equations for some medicinal and aromatic plants. J. Agric. Eng. Res. 74(3): 317-324.

Strahm, B. S., R. A. Flores, and D. S. Chung. 1995. Properties of dehydrated low-grade asparagus (Asparagus officinalis). J. Food Prot. 58(7): 804-809.

Sun, D. W., and J. L. Woods. 1993. The moisture content/relative humidity equilibrium relationship of wheat - A review. Drying Tech. 11(7): 1523-1551.

Van den Berg, C., and S. Bruin. 1981. Water activity and its estimation in food systems - Theoretical aspects. In Water Activity: Influences on Food Quality, 1-61. L. B. Rockland and G. F. Stewart, eds. New York, N.Y.: Academic Press.

Viswanathan, R., D. S. Jayas, and R. B. Hulasare. 2003. Sorption isotherms of tomato slices and onion shreds. Biosystems Eng. 86(4): 465-472.

Wang, N., and Brennan. 1991. Moisture isotherm characteristics of potatoes at four temperatures. J. Food Eng. 14(4): 269-287.

Yu, L., G. Mazza, and D. S. Jayas. 1999. Moisture sorption characteristics of freeze-dried, osmofreeze-dried, and osmo-air-dried cherries and blueberries. Trans. ASAE 42(1): 141-147.

Zink, F. J. 1935. Equilibrium moistures of some hays. Agric. Eng. 16(11): 451-452. 